\title{
Dos relatos literarios en defensa de la frágil condición humana.
}

\author{
Carlos Rey \\ Psicólogo Clínico, Psicoanalista. Barcelona. \\ carlosry@copc.cat
}

Salem (por Jerusalem), en la bahía de Massachusetts, fue uno de los puertos por el que entraron a Nueva Inglaterra los puritanos calvinistas ingleses, o seguidores del Puritanismo. Allí fundaron, en 1636, al poco de llegar, el Havard College. Salem también ha pasado a la historia de la intransigencia por sus famosos Juicios de Salem, o delirio colectivo-religioso a la caza de brujas. Unas 200 personas, principalmente mujeres, fueron acusadas de alucinar chufas y merecer ser ahorcadas por los bien pensantes. En esos sucesos se inspiró Arthur Miller para escribir El Crisol, una obra de teatro que denuncia otra caza de brujas, la protagonizada por el Macarthismo (Comisión de Actividades Antiamericanas, 1950). Luego vinieron los neo-puritanos y sicarios de Dios: Reagan y Busch, para delimitar, de nuevo y por la fuerza, el eje del bien y del mal.

En ese mismo puerto puritano de Salem, nació en 1804 el escritor Nathaniel Hawthorne, sabiéndose descendiente directo de uno de los jueces que condenaron a las brujas de Salem. Parece ser que nunca lo superó. De los 21 a los 33 años estuvo encerrado en su casa y en sí mismo. Purgando su culpa; elaborando literariamente el crimen de sus padres y al mismo tiempo denunciando los crímenes del Puritanismo. La letra escarlata es una de sus novelas más populares. La A de adultera es la letra de color escarlata que la comunidad puritana obligó llevar cosida a la altura de su pecho, bien visible, a una mujer que, teniendo una hija, estando su marido ausente, no quiso revelar el nombre de quien la embarazó. Esa misma pureza trasladada a la raza, provocó en pleno siglo XX que otros muchos millones llevaran cosida en sus ropas, diferentes maneras de señalar su no pertenencia a la pureza racial dominante.

Bien pudiera decirse que, a pesar de su extensa obra, Nathaniel Hawthone escribió sobre un sólo tema: las dificultades que tiene el ser humano para superar el determinismo psíquico del crimen de los padres... sin caer en la repetición de nuevos crímenes. Por eso escribió, uno tras otro, relatos en contra del determinismo a ultranza del Puritanismo. Esta cultura puritana de la predestinación de nuestra salvación o condenación eterna, es la que actualmente domina, no sólo la política internacional, sino también la clínica oficial de las sintomatologías psíquicas, pues se trabaja con el pre-juicio de que el ser humano es incapaz de procurarse su propia salvación, como de elaborar y hacerse responsable del por qué le pasan las cosas que le pasan. De allí que se quiera sustituir el determinismo psíquico de cada uno, por el determinismo del ordeno y mando, es decir, lo que determina el mismo amo de turno.

Nathaniel Hawthone fue muy respetado por sus colegas escritores. Poe le dedicó elogios y Melville le honró dedicándole Moby Dick. A Eliot le gustó mucho La casa de los siete tejados y a Borges sus cuentos, entre 
los que destaca La marca de nacimiento ${ }^{l}$. Marca o mancha, según la traducción, como metáfora de la condición humana. Cuento que sigue teniendo la lectura de que es peor eliminar la naturaleza humana que lidiar con ella. Aylmer es el protagonista del cuento. Él es un hombre de ciencia con pretensiones de dominar la naturaleza o condición humana. Trabaja en un laboratorio donde experimenta con remedios y venenos, es decir con Phármakon. Al poco de casarse empieza a repugnarle la mancha que su joven esposa tiene en la mejilla. Una minúscula «mano escarlata. (...) Una marca visible de la imperfección humana. (...) Era la falla fatal de la humanidad que, de una u otra manera, imprime imborrable la Naturaleza en todas sus creaciones, para anunciar que son temporales, $y$ finitas o que su perfección debe forjarse con trabajo y dolor. (...) La mano espectral que escribía el signo de la mortalidad. (...) De este modo, tras elegir la marca de nacimiento como el símbolo de la propensión de su mujer al pecado, el dolor, el desmedro y la muerte, Aylmer, movido por su sombría imaginación, no tardó en transformarla en algo abominable, que le infundió más desasosiego y verdadero horror... " ¡Ni que hubiera visto la mismísima cabeza de Medusa!

Por otra parte, lo que el autor de este cuento nos dice, es que la supuesta falta en la mujer es un síntoma para el hombre, por eso nuestro hombre de ciencia quiere eliminárselo... tanto a ella como así mismo. Así es que le propone a su mujer que le permita quitarle la marca de nacimiento de la mejilla. Y Georgiana, su mujer, que sabe que la verdad se abre paso a la inteligencia mediante los sueños, le pregunta si no recuerda lo soñado la noche pasada, pues le oyó gritar. Nuestro hombre de ciencia le dice que sí, que ha soñado la operación donde le eliminaba la falta, «pero cuanto más hondo llegaba el bisturí, más hondo se hundía también la pequeña mano, hasta que por fin pareció asir el corazón de Georgiana; y sin embargo el marido, implacable, quería seguir cortando, hasta arrancarla». Es evidente que la Ciencia avanza que es una barbarie, pues la castración o se simboliza o ya es amputación, cuando no exterminio. Por es que el hombre de ciencia insiste: «Estoy convencido de que la extirpación es perfectamente practicable. (...) Me siento plenamente seguro de hacer esa querida mejilla tan impecable como la otra. ¡Cuál será mi triunfo querida mía, cuando corrija lo que la Naturaleza dejó imperfecto en la más hermosa de sus obras! Ni siquiera Pigmalión, al ver que la mujer que había esculpido cobraba vida, habrá sentido un éxtasis mayor al que sentiré en ese momento. (...) No dudes de mi poder». Después de explicarle que es capaz de eliminarle la marca de nacimiento de su imperfección humana, como de fabricar el elixir de la inmortalidad, su mujer le dice: «Es terrible poseer ese poder y hasta soñar con poseerlo. (...) ¿Por qué tienes esa droga tan terrible?» Es evidente que para competir con la Religión: a ver quien tiene el agua bendita más efectiva para borrar el pecado original. «Entonces, me someto. [Termina diciendo su mujer] Beberé cualquier pócima que me traigas, pero será por la misma razón por que bebería también una dosis de veneno si me la ofrecieran tus manos». ¿Conseguirá la Ciencia sustituir a la Religión?... Remito al lector interesado a leer el final de este relato de ficción. También a impedir que la Ciencia actue como si fuera una ideología más de la perfección humana, de la estética o de la buena conducta. Porque, como dice Philip Roth en la novela sobre el actual puritanismo sexual de sus compatriotas, La mancha humana: «La mácula esta

\footnotetext{
1 La marca de nacimiento. Nathaniel Hawthorne. Alianza. Madrid, 1985.
} 
en cada uno de nosotros. Para siempre, inherente, constitutiva. (...) Por eso lavar esa mácula no es más que una broma. Incluso una broma bárbara. El fantasma de la pureza es terrorífico. Demente. ¿Qué es la búsqueda de la purificación sino una impureza más?» Y Alain Finkielkraut en Un corazón inteligente: «La mancha no es una sanción, es un hecho. Está ahí. No espera ni gracia ni redención, sino ser aceptada como una modalidad de nuestra condición».

Si fuera posible vacunarse contra ése o el actual puritanismo, el que nada quiere saber de la incomplitud del ser humano, nada mejor que releer la primera parte de los Apuntes del subsuelo de Dostoyevski². Un clásico, y no porque fue escrito en 1864, sino porque es un ejemplo vigente del pensamiento crítico y una digresión que quiere ser palo en la rueda de lo que progresa hacia la barbarie.

Dicen los estudiosos de Dostoyesvski que este relato fue escrito a la vuelta de su estancia a la sombra, en Siberia; al poco de morir su mujer y su hermano, y como respuesta a la novela doctrinaria ¿Qué hacer? (1863), escrita por su compatriota y también escritor Nikolái Chernishevski. ¿Qué hacer? es un compendio de buenas intenciones; más de lo mismo de lo ya dicho por las religiones, y que no tardarían en volver a imponerlo las ideologías totalitarias del siglo XX. Una proclama más, de las muchas que se han dado a lo largo de la historia de la humanidad, sobre el advenimiento de... ;El Hombre nuevo!

El Hombre Nuevo es una ideología más (¿o es la repetición de un fracaso y el fracaso de la repetición?) de cómo quieren unos pocos que seamos todos los demás. Un ser humano nuevo hecho a plantilla, a imagen y semejanza, no ya del ideal del yo sino del yo ideal. Imagen narcisista donde las haya, por mucho que se nos diga (Skinner, 1948) que caminamos Hacia una sociedad científicamente construida; ésa en la que sólo se podrá conjugar la acción en futuro perfecto. Un nuevo canto de sirena al culo de Narciso, otro retrato de Dorian Gray que hace de estampita en el timo de la ídem: hacernos creer en la existencia de un narcisismo racional, calculado, positivo.

Este utilitarismo materialista de lo que quieren que sea el ser humano, deviene en un autoritarismo o gobernanza de nuevo cuño. Neopuritanos para más señas, con pretensiones científicas en su ordeno y mando... cuando no deja de ser un exceso -y una falta de Ética- que el Saber actue como Poder. Máxime, cuando ese Saber hace gala de un desconocimiento -cuando no negación-de la condición humana. Pues, ese Hombre Nuevo con mayúsculas, es la enésima anunciación y resurrección del imaginario de un ser humano inmaculado, sin mancha ni falta, sin errores ni lapsus ni síntomas; e incluso vacunado contra su propia vulnerabilidad ontológica, fragilidad y caducidad. Un ser humano despojado de su subjetividad e inconsciente por decreto de los que nombran la evidencia científica en vano; aunque más riguroso sería decir que la nombran en beneficio de la homologación que precede al Orden Público. Un ser humano nuevo, sin fisuras, un feliz de la vida, un engendro de la Ciencia de la Felicidad alimentado únicamente con perdices. Producto de un cálculo predictivo, este hombre nuevo es el prototipo de la normalidad normativa y, por prescripción médica: normalidad química. Respuesta única a la pregunta sobre qué diantres será eso de la Salud Mental. Y es que la idea que ahora se lleva sobre la Salud es la que cotiza en bolsa: la Salud es una pre-enfermedad. No en balde, los que más saben hasta qué punto la Salud es... un negocio, son los que toda-

\footnotetext{
2 Apuntes del subsuelo. F.M. Dostoyevski. Alianza. Madrid, 1991.
} 
vía no han conseguido que sea un derecho. Y sin embargo, es su taxonomía la que aquí seguimos con tal devoción que al DSM bien podríamos denominarlo Devocionario de la Salud Mental.

De conseguirse, el hombre nuevo sería un producto humano, luego... lo que es un objeto ya no es un sujeto; si al caso otro Frankenstein, como el que elaboró literariamente Mary Shelley en 1818 y que tiene una lectura como relato de Ciencia Ficción, y otra lectura como reflexión sobre el límite o Ética de la Ciencia. El hombre nuevo también sería como un moderno Prometeo encadenado al sueño de la razón que no escucha la razón de los sueños. Un monstruo en definitiva, pues, es el resultado de extirparle al humano su determinismo psíquico e implantarle el determinismo del ordeno y mando: un chip con la voz de su amo deslocalizado; hoy ejercido al alimón entre los mercados y una Academia servil a sus intereses al proporcionarle evaluadores -que no clínicos- programados para hacer de su técnica un poder sobre el otro... como quien hace de su capa un sayo.

En este sentido Dostoyevski nos dice, en sus Apuntes del subsuelo, que toda idea del ser humano que se construya sin tener en cuenta su condición... humana, fracasará por partida doble: una, porque suele confundir el ideal del yo con el yo ideal, y otra porque no renuncia a forzar la imposibilidad de alcanzar ese ideal, en vez de elaborar las serias dificultades, cuando no imposibilidad, de curar, educar y gobernar. No en balde a Dostoyevski se le reconoce como un agudo observador del determinismo de la condición de ser humano, y por lo mismo de sus posibilidades...humanas. Un abogado de la condición humana y un notario que da fe de la existencia del sujeto del inconsciente, pues estos apuntes son el como si... de las razones del inconsciente. Por lo mismo, un escritor que piensa en paralelo a nuestras teorías psíquicas. En este relato, como en toda su obra, Dostokyeski nos habla de lo que anida en el psiquismo, y por tanto en la condición humana: la tensión de los contrarios. La tensión que existe y las chispas que pueden saltar, entre pulsiones contrarias, entre la pulsión de vida y la pulsión de muerte, entre Eros y Thánatos.

Los estudiosos de Dostoyevski también nos advierten de que, cuando en este relato, el autor dice «Ustedes», no se refiere a nosotros, sus lectores, sino a los que como Chernishevski nos quieren imponer la moto del Hombre Nuevo. A ellos les dice desde el subsuelo, que el ser humano no siempre hace ni hará sólo lo que le aconseja la razón y su interés. A veces «puede incluso que quiera hacer algo contra su propio interés, y a veces es absolutamente imperativo que lo haga. (...) Su propia, libre y franca voluntad, sus propios caprichos por bestiales que sean, su propia fantasía exacerbada a veces hasta la demencia... ésa es la más preciada ventaja que se ha pasado por alto, que no figura en ninguna clasificación, y contra la cual se estrellan de continuo todos los sistemas y todas las teorías»... que no tienen en cuenta la existencia del inconsciente, añado.

« $i Y$ de dónde sacan todos esos sabios que los deseos del hombre deben ser normales y ventajosos? ¿Cómo se les ocurre pensar que el hombre necesita inevitablemente lo racional y provechoso?" Cuando a punto estaba el narrador del subsuelo de decir que, metafóricamente hablando, sólo el diablo sabe de qué depende el deseo en el ser humano, se acuerda de los profetas de turno del Hombre Nuevo, y a ellos les dice: "es verdad que si algún día se descubre la verdadera fórmula de todos nuestros deseos, es posible que de pronto deje el hombre de desear, mejor dicho, de seguro que dejará de desear. ¿Porque a quién puede gustarle 
MÁRGENES DE LA PSIQUIATRÍA Y HUMANIDADES

desear de acuerdo con una fórmula matemática? Más todavía, dejaría al momento de ser humano para convertirse en cilindro de organillo o algo por el estilo». Según Dostoyevski, para los profetas del Hombre Nuevo, como para los de la invidencia científica «nuestros deseos son erróneos en la mayoría de los casos porque es errónea la noción que tenemos de nuestras ventajas», de lo que nos conviene. Y sin embargo, «cuando todo quede explicado y calculado sobre el papel, desaparecerán sin más los así llamados deseos. Porque llegado el día en que un deseo concuerde enteramente con la razón, entonces, por supuesto, razonaremos y no desearemos, porque [y nos lo dice al revés para que lo entendamos mejor] es a todas luces imposible desear lo que no es sensato, lo que va contra la razón y redunda en nuestro propio perjuicio... Y cuando toda razón y todo deseo puedan ser calculados, se podrá elaborar, y no es broma, una especie de tabla matemática, de modo que nuestros deseos se ajusten en todo punto a ella. (...) Ya ven ustedes que la razón no es más que razón y sólo satisface la facultad intelectiva del ser humano, mientras que el deseo es una manifestación de la totalidad de la vida humana, que incluye a la razón y a toda forma de especulación. Y aunque nuestra vida así manifestada resulta ser a menudo una porquería, es, no obstante, vida, y no mera extracción de una raíz cuadrada. (...) ¿Qué sabe la razón? La razón sabe únicamente lo que ha alcanzado a saber (y hay cosas que quizá nunca llegue a saber; lo cual no es un consuelo, pero ¿por qué no decirlo con franqueza?), mientras que la naturaleza humana actúa siempre como un todo, con todo aquello que lleva en sí, consciente $e$ inconscientemente, y aunque pueda desbarrar, vive no obstante». Intuyendo lo que le dirían los del ordeno y mando científico, sigue: «me repetirán una y otra vez que un hombre culto y en su pleno desarrollo, como será el hombre futuro, no puede querer a sabiendas lo que no es bueno para él, y eso es una certidumbre matemática. Estoy completamente de acuerdo. Es una certidumbre matemática. Pero les repito por centésima vez que aquí hay un caso, y sólo uno, en que un hombre puede desear, deliberada y conscientemente, algo perjudicial, estúpido, hasta sumamente estúpido, a saber: tener derecho a desear por sí mismo hasta lo sumamente estúpido y no estar obligado a desear sólo lo sensato. (...) Porque en todo caso salvaguarda lo más precioso e importante para nosotros, a saber, nuestra personalidad y nuestra individualidad. (...) El deseo puede, por supuesto, concertarse con la razón, especialmente si no se la abusa y se hace uso de ella con moderación; ello es útil y a veces puede ser digno de elogio». Con lo que ya no está de acuerdo el sujeto de este relato es con que no se pueda desear nada que no figure en una tabla matemática, pues, aunque las ciencias naturales y las matemáticas demostraran que el humano es un cilindro de organillo, un objeto, (en vez de un sujeto de pleno derecho), ya se encargaría éste de provocar el caos para llevarles la contraria. «Si dicen ustedes que también esto puede ser calculado matemáticamente - el caos-, de modo que la mera posibilidad de calcularlo de antemano pueda impedirlo y la razón acabe por triunfar, en tal caso el ser humano se volvería loco a propósito para deshacerse de la razón y salirse con la suya». Porque, al fin y al cabo, ser humano consiste en demostrar a cada momento que se es humano y no un cilindro de organi1lo. «Y demostrarlo aun a costa de su salud física; demostrarlo aun volviéndose troglodita», o mejor aún, cuestionando cualquier gobernanza sobre lo psíquico, o adecuación de nuestra subjetividad al autoritarismo científico, so pretexto de que tiene que coin- 
cidir con la aritmética, como antes tenía que coincidir con el credo, nación o raza dominante.

«¡Ah señores! ¿Qué clase de deseo será ése cuanto todo se reduzca a tablas matemáticas y aritmética, cuando lo único que importe sea que dos y dos son cuatro? (...) Ustedes tratan de apartar al ser humano de sus viejos hábitos y corregir su voluntad de acuerdo con las exigencias de la ciencia y el sentido común. ¿Pero cómo saben ustedes si el hombre no sólo puede, sino que debe, ser corregido así? ¿De dónde sacan que es de todo punto necesario corregir la voluntad humana?» Para quien así nos habla desde el subsuelo, no pasa de ser una suposición la existencia de deseos normales en el ser humano, por mucho que estén avalados por las conclusiones de la razón, la aritmética y la evidencia científica. Resumiendo: puede que la normalidad normativa «sea una conclusión lógica, pero puede no ser una ley humana». Y tiene razón, pues, es un atentado a la dignidad humana despojar al ser de su condición, y no escuchar la tensión de los contrarios que lo atenaza y que, en el mejor de los casos, lo determina a ser un neura toda la vida y sin posibilidades de cura alguna. ¿O acaso es una enfermedad su condición o naturaleza humana?

Desde el subsuelo se nos apunta que necesitamos incorporar a la idea de qué es ser humano (y qué puede llegar a ser), la existencia de la pulsión de muerte. Y no porque tenga más fuerza que la pulsión de vida, sino, porque al no tenerla en cuenta campa a sus anchas y actúa con mayor impunidad. Así nos habla Dostoyevsky de la insistencia de la pulsión de muerte: «El ser humano se desvive por construir y por abrir caminos; eso no tiene vuelta de hoja. ¿Pero por qué ama también, y ama con pasión, la destrucción y el caos? ¡A ver, explíquenme eso!» les inquiere a los que hacen del pensamien- to positivo su único pensamiento. (Discurso positivo que no dice nada tantas veces que parece que diga algo). Sin embargo, desde el subsuelo se nos apunta la teoría de que al ser humano le gusta construir pero no habitar su construcción, pues es su preferencia que lo habiten los animales domésticos, esto es: los borregos. «El ser humano es una criatura frívola e imprevisible y quizá gusta sólo del proceso de llegar a la meta, y no de la meta misma. ¿Y quién sabe? (nadie puede saberlo de cierto) quizá la única meta que persigue el humano consista únicamente en ese ir hacia ella, o, dicho de otro modo, consista en la vida misma, y no realmente en la meta, la que por supuesto, será algo así como dos y dos son cuatro, o sea, una fórmula; pero dos $y$ dos son cuatro no es vida, señores, sino el comienzo de la muerte». Pues, qué es sino morir de éxito lo que el humano teme, al encontrar lo que realmente busca. «Porque piensa que, una vez que haya encontrado lo que busca, ya no tendrá otra cosa que buscar. (...) Dos y dos son cuatro es una cosa insoportable. En mi opinión, dos y dos son cuatro es una pura desfachatez. Dos y dos son cuatro es algo así como un fantoche que se nos atraviesa en el camino con los brazos en jarras y nos escupe a la cara». Como cuando se insiste en que una palabra igual a un sentido, y punto. "¿Por qué están ustedes tan firmemente, tan triunfalmente, convencidos de que sólo lo normal y positivo - en una palabra sólo el bienestar - es ventajoso para el ser humano? ¿No se equivoca la razón en eso de las ventajas?» ¿En definir lo que nos conviene? "¿No es posible que al humano le guste otra cosa además del bienestar? ¿No es posible que le guste igualmente el sufrimiento, que el sufrimiento sea quizá tan ventajoso para él como el bienestar? (...) En cuanto a mi opinión personal, digo que amar sólo el bienestar es casi indecoroso. (...) No estoy aquí defendiendo el sufrimiento, ni tampoco 
MÁRGENES DE LA PSIQUIATRÍA Y HUMANIDADES

el bienestar», nos aclara, sino la libertad de ir contra el imperativo del dos y dos son cuatro, ya que, «después de dos y dos son cuatro no queda, por supuesto, nada que hacer, ni que aprender tampoco».

A diferencia de la literatura, y de las teorías psíquicas que intentan comprehender la subjetividad humana, la gobernanza neoliberal quiere dominarla; por eso recurre a la Ciencia, para que le calcule las probabilidades y le proporcione fórmulas predictivas que, a su vez, le permitan evaluar y gestionar los riesgos del desorden público. Para eliminarlos, nada mejor que el tratamiento único y exclusivamente basado en la invidencia de que la seguridad es preferible a la libertad. Sin embargo, desde el subsuelo se nos advierte que imponer el pensamiento positivo sobre la vulnerable condición humana, es tan suicida y criminal como construir centrales nucleares sobre las fallas tectónicas de la corteza terrestre. 